\title{
Evaluation the Effect of Different Soil Amendments on Physicochemical Property of Soda Saline-alkali Soil and Crop Yield in Northeast of China
}

\author{
Fan Xiao ${ }^{1}$, Hong bin Wang $^{2}$, and Bei bei Zhou ${ }^{3}$ \\ ${ }^{1}$ Xi'an University of Technology \\ ${ }^{2}$ Jilin Agricultural University \\ 3 Xi'an University of Technology
}

April 28, 2020

\begin{abstract}
Soil amendment is one of the most effective method to improve saline-alkali soil. In this paper, we verify the effect of 13 kinds of amendments and its combination on soil $\mathrm{pH}$ - metal cations content - exchangeable $\mathrm{Na}+$ 、 exchangeable sodium percentage (ESP)in the lab, and then choose the most 5 effective amendments both applying in both dry and paddy field to evaluate their improvement on soda saline-alkali soil and crop yield. The results showed that AL, AL $+\mathrm{Z}$ and AL $+\mathrm{ZH}$ treatments could significantly reduce the $\mathrm{pH}$ in soil solution and increase the content of metal cations. $\mathrm{Z}$ and $\mathrm{ZH}$ treatments could adsorb metal cations in soil. Whether in dry or paddy fields, all treatments could reduce the content of exchangeable Na+ in soil, and decrease by $38.62 \%-61.33 \%$ and $25.24 \%-71.53 \%$, respectively; All treatments could reduce soil exchangeable sodium percentage, and decrease by $0.14-0.22$ and $0.14-0.41$, respectively; $\mathrm{AL}, \mathrm{AL}+\mathrm{Z}$ and $\mathrm{AL}+\mathrm{ZH}$ treatments could improve soil organic matter content; All treatments could effectively improve the yield of crops, and increase $23.98 \%-60.75 \%$ and $52.51 \%$ - 260.21\%, respectively. The effect of AL treatment was the best in dry field and AL + ZH treatment was the best in paddy field of soda saline-alkali soil.
\end{abstract}

\section{Introduction}

In arid and semi-arid climate area, soil salination is one of the main reason for soil degradation, which seriously affects the sustainable development of agriculture (Qadir et al.2007;Qadir et al.2006). It was reported that about 7\% of the earth's surface area has been affected by soil salinization (Li et al. 2014; Zhao et al. 2019). Salinization and alkalinization of soil were the process of salt accumulation in surface soil, which is the main cause of soil quality degradation and plant growth restriction (Wang et al. 2009; Metternicht 2001), as well as reducing farmland productivity. Songnen Plain, located in the northeast of China $\left(43^{\circ} 30-48^{\circ} 40^{\prime} \mathrm{N} ; 121 \operatorname{deg} 30-127 \mathrm{deg} 00\right.$ 'E), with an annual precipitation from 300 to $600 \mathrm{~mm}$ (Wang et al. 2009), is one of the three largest soda alkali lands in the world (Zhou et al. 2019). There are more than $3.2 \times 10^{6}$ ha of soda saline-alkali land in Songnen Plain, of which is still increasing by $2.0 \times 10^{4}$ ha soda alkali land every year (Zhao et al. 2019). The properties of local soil, such as poor structure, high bulk density, easy to harden and low permeability, have seriously affected the normal growth and development of local plants. The reclamation practices of saline-sodic soils have been extensively investigated, including physical, chemical, and biological amelioration (Crescimanno and Santis 2004; Ferreraset al. 2006; Sadiq et al. 2007; Gill et al. 2008; Wong et al.2009; Li and Keren 2009), The government and researchers have 
conducted kinds of method to solve these problems, of which the most effective and practical method is chemical methods.

Presently, there are several Salinity chemical amendments, such as gypsum, phosphogypsum, calcium chloride, sulfuric acid, and aluminum sulfate etc (Ahmad et al. 2006; Mason et al. 1994; Amezketa et al. 2005; Luo, et al 2015). Among these amendments, gypsum is one of the most popular chemical amendment which have been proved to improve the rice yield. But the dissolution rates of gypsum is very low which will affect the improvement effect greatly. The dissolution rate of Aluminum sulfate is faster than that of gypsum, and the sedimentation capacity of soil colloidal particles is stronger than that of gypsum, so Aluminum sulfate can achieve rapid flocculation and sedimentation of colloidal particles in water. Furthermore, aluminum ions could produce $\mathrm{H}^{+}$ions by hydrolysis dissolve $\mathrm{CaCO}_{3}$ in soil to provide $\mathrm{Ca}^{2+}$ ions for improving saline sodic soils (Zhao et al. 2019). Recently, zeolite has been widely applied in agriculture production and environmental protection because of its high absorption capacity and cation exchanging capacity.

In Songnen plain, rice cultivation could help with improvement of the soda alkali land. However, under single irrigated rice cropping without additional soil amelioration, rice yields are still very low within the first four years (Luo and Sun, 2004). Thus in the paper, the primary objectives were to verify the effect of 13 kinds of amendments and its combination on soda saline-alkali soil in the lab, and then choose the most 5 effective amendments both applying in both dry and paddy field to evaluate their improvement on soda saline-alkali soil and crop yield. The studies in this paper are expected to provide instructive information for the chemical improvement and agricultural utilization of soda saline-alkali soils in the world.

\section{Materials and methods}

\subsection{Experimental site}

The experimental site is in Changchun Ling Town, Fuyu City, Jilin Province (N $45 \operatorname{deg} 23$ ' 33 ", E 125 deg 26' 54 ", altitude 132 meters), located in the center of northeast Songnen Plain, which is a typical area of moderate and severe soda alkali land. The area has an eastern temperate continental monsoon climate, with an annual average rainfall of $422 \mathrm{~mm}$, and little rainfall in spring. Most of the rainfall concentrated in summer, accounting for about $60 \%$ of the total annual rainfall. The annual illumination is sufficient, of which the sunslight could be more than 3000 hours and the frost free period is 145 days. The annual average evaporation is $1733 \mathrm{~mm}$, and the annual average temperature is 4.4 . The basic characteristics of the local are listed in Table 1.

\subsection{Experimental design}

The experiments in this paper were conducted both in lab and in field. In the lab, we evaluated the effect of 6 amendments (Citric acid, phosphogypsum, zeolite, acidified zeolite, aluminum sulfate and polyaluminium chloride) and its combinations amendments (7 treatments) on the sedimentation in soda saline-alkali soil. Together with one control treatment, 14 treatments were set up as follows: 1 . Control, no amendments (CK) 2. Citric acid (NM) 3. Phosphogypsum (LS) 4. Aluminum sulfate + citric acid (AL $+\mathrm{NM})$ 5. Aluminum sulfate + phosphogypsum $(\mathrm{AL}+\mathrm{LS}) 6$. Aluminum sulfate + citric acid + phosphogypsum $(\mathrm{HH})$ 7. Zeolite (z) 8. Acidified zeolite $(\mathrm{ZH})$ 9. Aluminum sulfate (AL) 10. Aluminum sulfate + zeolite $(\mathrm{AL}+\mathrm{Z}) 11$. Aluminum sulfate + acidified zeolite $(\mathrm{AL}+\mathrm{ZH})$ 12. Poly Aluminum chloride (ALCL) 13. Polyaluminium chloride + zeolite (ALCL + Z) 14. Polyaluminium chloride + acidified zeolite (ALCL + ZH); each treatment had three replications.

Sedimentation experiment

In each treatment, $200.0 \mathrm{~g}$ air-dried soil samples were sieved to $2 \mathrm{~mm}$ and then were put it into a glass beaker of $2000 \mathrm{ml}$. Each glass beaker add $0.2 \%, 0.4 \%, 0.6 \%$ and $0.8 \%$ in mass amendments(equal to 
$0.4 \mathrm{~g} 、 0.8 \mathrm{~g} 、 1.2 \mathrm{~g} 、 1.6 \mathrm{~g})$, respectively. Then $1000 \mathrm{ml}$ of distilled water was added into the glass beaker Stir the soil-water mixture quickly with magnetic stirrer for $2 \mathrm{~min}$, and then stirrer slowly for $4 \mathrm{~min}$. Finally, the mixture was put into a measuring cylinder of $1500 \mathrm{ml}$. After $24 \mathrm{~h}$ ' standing, the sedimentation rate was measured. In order to simulate the rice soaking process, the ion composition was measured after 7 days' standing.

Field experiments:

After the experiments in the lab were finished, 5 soil amendments were chosen as the best amendments, which were applied into the dry field and paddy field.

In the dry field experiment, 6 treatments were set up, including control, without amendment $(\mathrm{CK})$, zeolite $(\mathrm{Z})$, acidified zeolite $(\mathrm{ZH})$, aluminum sulfate $(\mathrm{AL})$, aluminum sulfate + zeolite $(\mathrm{AL}+\mathrm{Z})$, aluminum sulfate + acidified zeolite $(\mathrm{AL}+\mathrm{ZH})$. each treatment has three replicates.

The amendments were all spread on the surface of the soil, and then were all ploughed into the ground by mechanical ploughing. The corn variety is Jingke 968. The application amount of fertilizer $\left(\mathrm{N}-\mathrm{P}_{2} \mathrm{O}_{5}-\mathrm{K}_{2} \mathrm{O}\right.$ : 27-14-14)was $750 \mathrm{~kg} / \mathrm{ha}$ and the application amount of amendments was $15 \mathrm{t} / \mathrm{ha}$, which is equivalent to $0.6 \%$ of the soil quality. The experiment was performed from April 2017 to October 2018, which have 2 consecutive growing seasons. $0-20 \mathrm{~cm}$ soil samples were collected and measured, together with the yield every year. Amendments was applied in paddy field during rice soaking. The amendments application rate was the same to that in dry field. The rice variety was Jihong 6 , and all farming practices and field management were performed according to the local cultivation in the study area.

\subsection{Experimental methods}

In sedimentation test, soil equilibrium solution was centrifuged and $\mathrm{pH}$ was measured by PHS-3C $\mathrm{pH}$ meter potential method; electrical conductivity (EC) was measured by DDB-303A portable electrical conductivity machine of Shanghai Leici; $\mathrm{Na}^{+}$was measured by flame photometry; $\mathrm{Ca}^{2+}$ and $\mathrm{Mg}^{2+}$ were measured by atomic absorption flame photometry. Calculate the sodium adsorption ratio.

$$
S A R=\frac{\mathrm{Na}^{+}}{\sqrt{\frac{\left(\mathrm{Ca}^{2+}+\mathrm{Mg}^{2+}\right)}{2}}}
$$

The soil micro-aggregates were determined by wet sieving method. The exchangeable $\mathrm{Na}^{+}$content was determined by ammonium acetate ammonium hydroxide exchange flame photometry, and the cation exchange capacity (CEC) was determined by sodium acetate flame photometry. Determination of organic matter content by potassium dichromate oxidation.

\section{Results}

\subsection{Effect of different amendments on physical and chemical properties of soda saline-alkali soil} 3.1.1 Effect of different amendments on settling properties of suspension in soda saline-alkali
soil

The settlement test could reflect the improvement of different amendments on soda saline-alkali soil, and then the suitable amendments would be selected for field application. At the initial of the experiment, the water and soil in the settling bottle were mixed well and observed in the static state. After the application of NM, AL and ALCL, the suspension immediately began to settled down and the settling velocity was very fast. However, the settling speed of $\mathrm{AL}+\mathrm{NM}, \mathrm{AL}+\mathrm{LS}, \mathrm{HH}, \mathrm{AL}+\mathrm{Z}, \mathrm{AL}+\mathrm{ZH}, \mathrm{ALCL}+\mathrm{Z}$ and 
ALCL + ZH was significantly slower than that with NM, AL and ALCL. There was no significant change in the treatment of LS, Z and ZH in a short time. After 24 hours of static state, the settlement phenomena were observed. The soil suspension with LS and ZH treatment became clear, but there was no difference was found in the CK and treatment with Z. Moreover, soil suspension with other treatments has completely settled down, and the water column is clear and transparent.

In order to further evaluate the effect of different amendments dosage on soda saline-alkali soil, the average height of soil column and water column of each treatment after one week's standing was showed in Fig 1. With the increase of the added amount, the settling velocity of the soil column became faster and the effect became better (Fig.1). It could be found in Fig.1 that CK had no sedimentation and the solution was still a suspension; $\mathrm{Z}$ and $\mathrm{ZH}$ have a certain degree of colloidal flocculation effect but Z and ZH were not as good as those with other amendments; the rest of the treatment has already been settled. The results showed that all treatments could promote soil colloid flocculation.

\subsubsection{Effect of different amendments on chemical properties of equilibrium solution of soda saline-alkali soil}

In order to know the effect of different amendments on chemical properties of soda saline-alkali soil, $\mathrm{pH}, \mathrm{EC}$, $\mathrm{Na}^{+}, \mathrm{Ca}^{2+}, \mathrm{Mg}^{2+}$ and sodium adsorption ratio (SAR) of soil balance solution were all determined and the results were shown in Table 2. From table 2, we can see that all treatments with NM, LS and AL could significantly reduce the $\mathrm{pH}$ of soil equilibrium solution $(\mathrm{P}<0.05)$ and the highest $\mathrm{pH}$ value of 9.15 was in $\mathrm{CK}$ (Zhou et al. 2019), but the lowest $\mathrm{pH}$ value of 7.53 was in AL + LS treatment. The EC can reflect the soluble salt content of soda saline-alkali soil. Except Z and ZH treatment, other treatments increased the EC of soil equilibrium solution comparing to $\mathrm{CK}$, the increased range was $0.58-1.8$, and there was significant difference with CK $(\mathrm{P}<0.05)$, and the lowest EC of $\mathrm{Z}$ treatment was $0.89 \mathrm{dS} / \mathrm{m}$, the highest EC of ALCL treatment was $2.85 \mathrm{dS} / \mathrm{m}$. Sodium content reflects soda saline-alkali soil content of sodium salt. All treatments except $\mathrm{Z}$ and $\mathrm{ZH}$ increased $\mathrm{Na}^{+}$in soil equilibrium solution, and there was significant difference between them and CK $(\mathrm{P}<0.05)$. The content of $\mathrm{Na}^{+}$in soil equilibrium solution of $\mathrm{Z}$ treatment was the lowest, with the value of $177 \mathrm{mg} / \mathrm{L}$, and the $\mathrm{AL}$ was the highest, with the value of $677.65 \mathrm{mg} / \mathrm{L}$. Except for all treatments in which $\mathrm{Z}$ and $\mathrm{ZH}$ were involved, all treatments could significantly increase the content of $\mathrm{Ca}^{2+}$ in soil equilibrium solution $(\mathrm{P}<0.05)$. The content of $\mathrm{Ca}^{2+}$ was the lowest in $\mathrm{Z}$ and $\mathrm{ZH}$ treatments; $\mathrm{Z}$ and $\mathrm{ZH}$ treatment were also the treatment with the lowest $\mathrm{Mg}^{2+}$ content. Except $\mathrm{AL}+\mathrm{Z}$ treatment, all the treatments that $\mathrm{AL}$ participated in significantly increased the content of $\mathrm{Mg}^{2+}$ in soil equilibrium solution $(\mathrm{P}<0.05)$; $\mathrm{Z}$ and ZH treatment reduced the SAR of soil equilibrium solution, and the other treatments increased the SAR of soil equilibrium solution except HH treatment. The smaller the SAR value is, the improvement will be better. The main reason is that the settlement test was conducted in a semi sealed environment without iron exchange, and the main components of the soda saline-alkali soil in the Northeast Songnen Plain are $\mathrm{Na}_{2} \mathrm{CO}_{3}$ and $\mathrm{NaHCO}_{3}$. Then SAR value rise, which is equivalent to a process of leaching with irrigated water in the field production. In this experiment, the higher SAR of the equilibrium solution means more salt was washed away. The same is true for EC. The increase of EC value is caused by the increase of the content of various ions in the equilibrium solution. The higher the EC value of the equilibrium solution, the better the salt was washed away.

The results in table 2 also showed that all chemical amendments have excellent improvement effects on soda saline-alkali soil. But considering about the practicability, the high price of NM and ALCL will limit the application. Moreover, the dissolution rate of LS was too slow at room temperature. So 3 amendments, Z, $\mathrm{ZH}, \mathrm{AL}$, and 2 combinations, $\mathrm{AL}+\mathrm{Z}$ and $\mathrm{AL}+\mathrm{ZH}$, were selected for field experiment. 


\subsection{Effect of different amendments on soil properties and crop yield}

\subsubsection{Effect of different amendments on soil microaggregates}

The composition of soil microaggregate affects the ability of soil water and nutrient supply, which is an important indicator for soil fertility. The effect of different amendments on soil microaggregates was illustrated in Fig 2. As shown in Fig 2, the microaggregates contents with the size less than $0.001 \mathrm{~mm}$ and $0.01-0.005 \mathrm{~mm}$ decreased, but the microaggregates of $0.05-0.25 \mathrm{~mm}$ and $0.25-1 \mathrm{~mm}$ increased. Comparing to CK, the content of microaggregate with the size of less than $0.001 \mathrm{~mm}$ and $0.001-0.005 \mathrm{~mm}$ decreased by $28.16 \%, 35.06 \%$, $55.46 \%, 41.67 \%$ and $48.85 \%$, respectively. The application of different amendments significantly reduced the proportion of microaggregate that less than $0.001 \mathrm{~mm}$ and $0.001-0.005 \mathrm{~mm}$ particles $(\mathrm{P}<0.05)$; The proportion aggregate with the size of $0.05-0.25 \mathrm{~mm}$ and $0.25-1 \mathrm{~mm}$ increased significantly $(\mathrm{P}<0.05)$, and aggregate size of $0.05-0.25 \mathrm{~mm}$ has a whopping percentage, which increased by $19.05 \%, 19.05 \%, 52.78 \%$, $32.94 \%$ and $39.68 \%$, respectively. AL treatment had the highest proportion of $0.05-0.25 \mathrm{~mm}$ aggregate size, which indicated that under dry farming conditions, AL treatment has the strongest ability to promote the aggregation of small aggregates to large aggregates. As shown in Fig 2, The effect of different amendments on paddy soil microaggregates was consistent with that of dry land. The application of different amendments significantly reduced the proportion of microaggregate of less than $0.001 \mathrm{~mm}$ and $0.001-0.005 \mathrm{~mm}$ particles $(\mathrm{P}<0.05)$, comparing to $\mathrm{CK}$, the content of microaggregate with the size of less than $0.001 \mathrm{~mm}$ and $0.001-$ $0.005 \mathrm{~mm}$ decreased by $34.21 \%, 38.95 \%, 55.00 \%, 45.53 \%$ and $49.74 \%$, respectively; However, the proportion of 0.05-0.25 mm and 0.25-1 mm aggregates increased significantly $(\mathrm{P}<0.05)$, the content of microaggregate with the size of $0.05-0.25 \mathrm{~mm}$ and $0.25-1 \mathrm{~mm}$ increased by $37.61 \%, 42.20 \%, 69.21 \%, 54.59 \%$ and $62.84 \%$, respectively; the proportion of $0.05-0.25 \mathrm{~mm}$ particle microaggregate increased the most.

\subsubsection{Effect of different amendments on exchangeable $\mathrm{Na}^{+}, \mathrm{CEC}$ and ESP in soil}

Exchangeable $\mathrm{Na}^{+}$and ESP are both important indexes to measure soda saline-alkali soil, ESP is the percentage of exchangeable $\mathrm{Na}^{+}$in CEC, which reflects the alkalization degree of soda saline-alkali soil. The effects of different amendments on exchangeable $\mathrm{Na}^{+}, \mathrm{CEC}$ and ESP in soil are shown in Table 3, as shown in Table 3, all treatments were significantly reduced the content of exchangeable $\mathrm{Na}^{+}$and ESP in dry field and paddy field and increased CEC slightly.

The contents of soil exchangeable $\mathrm{Na}^{+}$in dry field were reduced by $38.6 \%, 42.5 \%, 52.2 \%, 57.7 \%$ and $61.3 \%$, respectively; There was no significant difference between the treatments with $\mathrm{Z}$ and $\mathrm{ZH}(\mathrm{P}>0.05)$ and there was also no significant difference among the treatments with $\mathrm{AL}, \mathrm{AL}+\mathrm{Z}$ and $\mathrm{AL}+\mathrm{ZH}(\mathrm{P}>0.05)$, but significant difference were found in treatment with $\mathrm{Z}$ and $\mathrm{ZH}(\mathrm{P}<0.05)$ where CEC has been increased slightly and ESP decreased significantly of which each treatment could reduce 14.24\%, 15.85\%, 19.21\%, $20.89 \%$ and $22.23 \%$, respectively. Each treatment could significantly reduce the content of soil exchangeable $\mathrm{Na}^{+}(\mathrm{P}<0.05)$ in paddy field and decreased by $25.2 \%, 29.7 \%, 50.2 \%, 62.7 \%$ and $71.5 \%$, respectively; ESP decreased significantly, each treatment could reduce 14.43, 16.65, 29.90, 35.95 and 40.92 percentage points, respectively. $\mathrm{AL}+\mathrm{ZH}$ treatment had the best effect.

\subsubsection{Effects of different amendments on soil organic matter content}

Soil organic matter is a complex mixture of organic compounds such as plant residues, microbial products and rhizosphere inputs in various stages of decomposition (Kögel-Knabner and Rumpel, 2018; Lehmann and Kleber, 2015), which will influence physical, chemical and biological activities and processes in the soil (Loveland and Webb, 2003; Murphy, 2015). Besides, organic matter has the potential influence to crop yields via any of these processes above (Oelofse et al., 2015). The effect of different amendments on soil organic matter content was illustrated in Fig 3, as shown in Fig 3, comparing to CK, treatments with Z and ZH could increase the organic matter content slightly. AL, AL $+\mathrm{Z}$ and $\mathrm{AL}+\mathrm{ZH}$ could significantly increase the organic matter content and the results were consistent in dry field and paddy field which showed that the application of aluminum sulfate could improve the content of soil organic matter. 


\subsubsection{Effects of different amendments on yield components and yield of crops}

Crop yield components and yield can reflect the growth of crops and directly reflect the improvement effect. The effects of different amendments on corn yield components and yield were presented in Table 4, rice yield components and yield in Table 5. As shown in Table 4, compared to CK, all treatments significantly improved yield components and significantly increased yield in corn. In the first year, AL treatment had the highest spike number, spike grain number and 1000 grain weight, all treatments had significant difference to that of $\mathrm{CK}$ in corn yield $(\mathrm{P}<0.05)$. The spike number of $\mathrm{AL}$ treatment was the highest, and there was no significant difference among other treatments compared to CK $(\mathrm{P}>0.05)$; No significant difference were found between treatments of $\mathrm{AL}, \mathrm{AL}+\mathrm{Z}$ and $\mathrm{AL}+\mathrm{ZH}(\mathrm{P}>0.05)$, but there was significant difference between treatments of $\mathrm{ZH}$ and $\mathrm{Z}(\mathrm{P}<0.05)$. The 1000 grain weight of $\mathrm{AL}$ treatment was the highest, which was significantly different with other treatments $(\mathrm{P}<0.05)$; the results of the two years were basically the same. All treatments could significantly increase corn yield, AL treatment had the highest yield, with an average yield of $10394 \mathrm{~kg} / \mathrm{hm}^{2}$ and was increased by $60.75 \%$. The best treatment for dry field improvement was AL.

As shown in Table 5, in the first year, spike number and 1000 grain weight of rice with AL+ZH treatment was the highest. There was significant difference between all treatments and $\mathrm{CK}$ treatment $(\mathrm{P}<0.05)$. AL treatment had the highest spike grain number, there was no significant difference between $\mathrm{Z}$ and $\mathrm{ZH}$ treatment with CK treatment $(\mathrm{P}>0.05)$, the results showed that treatments with $\mathrm{Z}$ and $\mathrm{ZH}$ had no significant effect on the spike grain number; The spike number, spike grain number and 1000 grain weight of AL+ZH treatments were the highest in the second year. The results of the two years were basically the same. Treatment with $\mathrm{AL}+\mathrm{ZH}$ was the highest in rice yield and the average yield is $7971.5 \mathrm{~kg} / \mathrm{hm}^{2}$. The rice yield was increased by $260.21 \%$. The effect of AL treatment was the best in dry field, the effect of AL $+\mathrm{ZH}$ treatment is the best in paddy field.

\section{Discussion}

With the application of chemical amendment, the $\mathrm{pH}$ of Soil equilibrium solution decreased, but the EC, metal cation and SAR increased dueing to the $\mathrm{H}^{+}$produced by hydrolysis of aluminum ions amendments, which will result in the dissolution of the soil metal carbonate and the entry of cations into the equilibrium solution (Luo, et al 2015). Aluminum or polymer aluminum ions produced after hydrolysis of aluminum sulfate (Zhou et al. 2015), which promotes the formation of soil colloid agglomerates and microaggregates; Zeolite adsorbs colloidal clay particles to form aggregates to increase the number of large particle size aggregates ( $\mathrm{Li} \mathrm{H}$, et al. 2009), and then improve the soil structure. Reduced exchangeable $\mathrm{Na}^{+}$and ESP is probably due to strong ion exchange and adsorption capacity of zeolite, which adsorbs $\mathrm{Na}^{+}$(Zhang et al. 2016), and by producing $\mathrm{H}+$ through hydrolysis, aluminum sulfate rapidly reduced soil $\mathrm{pH}$ and promoted the dissolution of metal carbonate to provide $\mathrm{Ca}^{2+}$ and $\mathrm{Mg}^{2+}$ for replacing exchangeable $\mathrm{Na}^{+}$in soda salinealkali soil (Zorpas A A et al., 2000; Zhou et al., 2019). The increase of organic matter content is mainly because the poor physical and chemical properties of soil which has been improved by the application of aluminum sulfate and zeolite, and promote the growth of crops, as well as the development of root system. The developed roots could further excrete organic acids and produce more organic matter (Wang et al 2006). Moreover, a large amount of straw remained during harvest is straw returning to the field, which is also the reason for the increased of organic matter content (Zhou et al 2015). On the whole, due to the improvement of soil physical and chemical properties and the increased of organic matter content (Wang et al, 2006), different amendments could have a positive effect on crop yield components and significantly increased crop yields and the yield increased significantly. 


\section{Conclusion}

According to the settlement experiment, aluminum ion amendments could significantly reduce the $\mathrm{pH}$ value of soil equilibrium solution, significantly improve EC, metal cation content and SAR of soil equilibrium solution; zeolite and acidified zeolite could significantly reduce EC, metal cation content and SAR of soil equilibrium solution. It can be seen from the field experiments that the application of aluminum sulfate and zeolite could reduce the number of small and medium-sized aggregates, increase large aggregates, improve the permeability of soil, and significantly reduce the exchangeable $\mathrm{Na}^{+}$and ESP of soil. The improvement of soil structure is conducive to the leaching of salt; the application of aluminum sulfate could improve the soil organic matter content; the application of aluminum sulfate and zeolite could improve the yield of corn and rice. The results showed that the most effective way to improve soda alkali soil was to apply aluminum sulfate alone in dry field, and the most effective way was to combine aluminum sulfate and acidified zeolite in paddy field.

\section{Acknowledgements}

The study was funded by the National Natural Science Foundation of China (41830754,41807131 and 41977007),Natural Science Foundation of Shaanxi province of China (2019JQ-537) and China Postdoctoral Science Foundation (2019M653707), Research project of State Key Laboratory of Eco-hydraulics in Northwest Arid Region of China (2019KJCXTD-4 and QJNY-2019-01).

\section{References}

Ahmad, S., Ghafoor, A., Qadir, M., Aziz, M.A., 2006. Amelioration of a calcareous saline-sodic soil by gypsum application and different crop rotations. Int. J. Agric. Biol. 8, 142-146. https://www.researchgate.net/publication/2289

Amezketa, E., Aragues, R., Gazol, R., 2005. Efficiency of sulfuric acid, mined gypsum, and two gypsum byproducts in soil crusting prevention and sodic soil reclamation. Agron. J. 97 (3), 983-989. http://agron.scijournals.org/cgi/cor

Chi, C.M., Zhao, C.W., Sun, X.J., Wang, Z.C., 2012. Reclamation of saline-sodic soil properties and improvement of rice (Oriza sativa L.) growth and yield using desulfurized gypsum in the west of Songnen Plain northeast China. Geoderma 187, 24-30. https://doi.org/10.1016/j.geoderma.2012.04.005

Crescimanno G, Santis AD (2004) Bypass flow, salinization and sodication in a cracking clay soil. Geoderma 121:307-321. https://doi.org/10.1016/j.geoderma.2003.11.014

Ferreras, L., Gomez E., Toresani, S., Firpo, I., Rotondo, R., 2006. Effect of organic amendments on some physical, chemical and biological properties in a horticultural soil. Bioresour Technol 97:635-640. https://doi.org/10.1016/j.biortech.2005.03.018

Gill, J.S., Sale P.W.G., Tang, C., 2008. Amelioration of dense sodic subsoil using organic amendments increases wheat yield more than using gypsum in a high rainfall zone of southern Australia. Field Crops Res 107:265-275. https://doi.org/10.1016/j.fcr.2008.02.014

Kogel-Knabner, I., Rumpel, C., 2018. Advances in molecular approaches for understanding soil organic matter composition, origin, and turnover: a historical overview. Adv. Agron. 149, 1-48. https://doi.org/10.1016/bs.agron.2018.0

Lehmann, J., Kleber, M., 2015. The contentious nature of soil organic matter. Nature 528,60-68. https://doi.org/10.1038/nat

Li, F., Keren, R., 2009. Calcareous sodic soil reclamation as affected by corn stalk application and incubation: a laboratory study. Pedosphere 19:465-475. https://doi.org/10.1016/S1002-0160(09)60139-9

Li, H.,Shi, W., Shao, H., et al.,2009. The remediation of the lead polluted garden soil by natural zeolite. Journal of Hazardous Materials 169(1-3): 1106-1111. https://doi.org/10.1016/j.jhazmat.2009.04.067 
Li, J., Pu, L., Han, M., Zhu, M., Zhang, R., Xiang, Y., 2014. Soil salinization research in China: Advances and prospects. Journal of Geographical Sciences. 24(5): 943-960. https://doi.org/10.1007/s11442-014-11302

Loveland, P., Webb, J., 2003. Is there a critical level of organic matter in the agricultural soils of temperate regions: a review. Soil Tillage Res. 70, 1-18. https://doi.org/10.1016/s0167-1987(02)00139-3

Luo, J., Wang, L., Li, Q., Zhang, Q., He, B., Wang, Y., Qin, L., Li, S., 2015. Improvement of hard saline-sodic soils using polymeric aluminum ferric sulfate (PAFS). Soil \& Tillage Research 149 (2015) 12-20. https://doi.org/10.1016/j.still.2014.12.014

Luo, X., Sun, G., 2004. Desalinization process through cultivating rice in heavy salinized meadow soil containing saline-alkaline patches. Ecol. Environ. 13 (1), 47-50 (in Chinese with English abstract). https://doi.org/10.1300/J064v24n01_09

Mason, M.G., Porter, W.M., Cox, W.J.,1994. Effect of an acidifying nitrogen-fertilizer and lime on soil-pH and wheat yields. 2. Plant response. Aust. J. Exp. Agric. 34 (2), 247-253. https://doi.org/10.1071/EA9940247

Metternicht, G (2001) Assessing temporal and spatial changes of salinity using fuzzy logic, remote sensing and GIS: foundations of expert system. Ecol Model 144:163-179. https://doi.org/10.1016/s0304-3800(02)00009-1

Murphy, B.W., 2015. Impact of soil organic matter on soil properties-a review with emphasis on Australian soils. Soil Res. 53, 605-635. https://doi.org/10.1071/SR14246

Oelofse, M., Markussen, B., Knudsen, L., Schelde, K., Olesen, J.E., Jensen, L.S., Bruun, S., 2015. Do soil organic carbon levels affect potential yields and nitrogen use efficiency? An analysis of winter wheat and spring barley field trials. Eur. J. Agron. 66, 62-73. https://doi.org/10.1016/j.eja.2015.02.009

Qadir M., Noble A. D., Schubert S., et al., 2006. Sodicity-induced land degradation and its sustainable management: problems and prospects. Land Degradation and Development 17(6):661-676. https://doi.org/10.1002/ldr.751

Qadir M., Oster J.D., Schubert S., et al, 2007. Phytoremediation of sodic and saline-sodic soils. Advances in Agronomy. 96:197-247. https://doi.org/10.1016/S0065-2113(07)96006-X

Sadiq, M., Hassan, G., Mehdi, S.M., Hussain, N., Jamil, M., 2007. Amelioration of saline sodic soils with tillage implements and sulfuric acid application. Pedosphere 17:182-190. CNKI:SUN:TRQY.0.2007-02-006

Wang et al., 2006. Effect of Aluminum Sulfate on Chemical Characteristics of Soda Alkali-Saline Soil and Rice Yield. Journal of Jilin Agricultural 28(6): 652-655+659. (In Chinese with English abstract). https://doi.org/10.13327/j.jjlau.2006.06.016

Wang et al., 2006. Study on Function of Aluminum Sulfate on Soda Alkali -saline Soil Improvement. Journal of Soil and Water Conservation 20(4):50-53. (In Chinese with English abstract). https://doi.org/10.13870 /j.cnki.stbcxb.2006.04.012

Wang, L., Seki, K., Miyazaki, T., Ishihama, Y., 2009. The causes of soil alkalinization in the Songnen Plain of Northeast China. Paddy Water Environ. 7 (3), 259-270. https://doi.org/10.1007/s10333-009-0166-x

Wong, V.N.L., Dalal, R.C., Greene, R.S.B., 2009. Carbon dynamics of sodic and saline soils following gypsum and organic material additions: a laboratory incubation. Appl Soil Ecol 41:29-40. https://doi.org/10.1016/j.apsoil.2008.08.00

Zhang, Y., Li, S., Sun, X., 2016 Improvement Effects of Different Amendments on the Coastal Saline-alkali Soil. Journal of Irrigation and Drainage 35(5):67-73. (In Chinese with English abstract) https://doi.org/10.13522/j.cnki.ggps.2

Zhao, X., Zhu, M., Guo, X., Wang, H., Sui, B., Zhao, L., 2019.Organic carbon content and humus composition after application aluminum sulfate and rice straw to soda saline-alkaline soil. Environmental Science and Pollution Research 26(14), 13746-13754. https://doi.org/10.1007/s11356-018-2270-1 
Zhou, et, al. 2019. Additional application of aluminum sulfate with different fertilizers ameliorates salinesodic soil of Songnen Plain in Northeast China. Journal of Soils And Sediments 19(10):3521-3533. https://doi.org/10.1007/s11 019-02311-9

Zhou, et, al., 2015. Studies on Rapid Amendment of Soda Saline-Alkaline Paddy Fields. Journal of Jilin Agricultural Sciences 40(5):53-57. (In Chinese with English abstract) https://doi.org/10.16423/j.cnki.10038701.2015.05.014

Zorpas A A,Constantinides T,Vlyssides A G., et al., 2000. Heavy metal uptake by natural zeolite and metals partitioning in sewage sludge compost. Bioresource Technology 72(2): 113-119. https://doi.org/10.1016/s09608524(99)00110-8

Table.1 Basic characteristics of tested soil

\begin{tabular}{lllll}
\hline $\begin{array}{l}\text { Types of cultivated } \\
\text { land }\end{array}$ & Treatment & $\begin{array}{l}\text { Exchangeable } \\
\mathrm{Na}^{+}(\mathrm{cmol} / \mathrm{kg})\end{array}$ & $\mathrm{CEC}(\mathrm{cmol} / \mathrm{kg})$ & $\mathrm{ESP}($ \\
\hline Dry field & $\mathrm{CK}$ & $3.62 \pm 0.36 \mathrm{a}$ & $10.40 \pm 0.30 \mathrm{~b}$ & 34.81 \\
& $\mathrm{Z}$ & $2.22 \pm 0.52 \mathrm{~b}$ & $10.79 \pm 0.15 \mathrm{~b}$ & 20.57 \\
& $\mathrm{ZH}$ & $2.08 \pm 0.19 \mathrm{~b}$ & $10.97 \pm 0.25 \mathrm{ab}$ & 18.96 \\
& $\mathrm{AL}$ & $1.73 \pm 0.06 \mathrm{c}$ & $11.09 \pm 0.13 \mathrm{ab}$ & 15.60 \\
& $\mathrm{AL}+\mathrm{Z}$ & $1.53 \pm 0.29 \mathrm{c}$ & $10.99 \pm 0.64 \mathrm{ab}$ & 13.92 \\
Paddy field & AL+ZH & $1.40 \pm 0.38 \mathrm{c}$ & $11.22 \pm 0.22 \mathrm{a}$ & 12.48 \\
& $\mathrm{CK}$ & $5.61 \pm 0.76 \mathrm{a}$ & $13.40 \pm 0.50 \mathrm{~b}$ & 56.79 \\
& $\mathrm{Z}$ & $5.35 \pm 0.62 \mathrm{~b}$ & $13.43 \pm 0.40 \mathrm{~b}$ & 42.36 \\
& $\mathrm{ZH}$ & $3.79 \pm 0.56 \mathrm{c}$ & $13.33 \pm 0.25 \mathrm{~b}$ & 40.14 \\
& $\mathrm{AL}$ & $2.84 \pm 0.49 \mathrm{~cd}$ & $14.09 \pm 0.17 \mathrm{a}$ & 26.89 \\
& $\mathrm{AL}+\mathrm{Z}$ & $2.17 \pm 0.28 \mathrm{~d}$ & $13.63 \pm 1.22 \mathrm{ab}$ & 20.84 \\
& $\mathrm{AL}+\mathrm{ZH}$ & & & 15.87 \\
\hline
\end{tabular}

Table.2 Effect of different amendments on pH, Electrical conductivity (EC), Na+, Ca2+, Mg2+ and sodium adsorption ratio (SAR) of soil equilibrium solution

\begin{tabular}{lllllll}
\hline Treatment & $\mathrm{pH}$ & $\mathrm{EC}(\mathrm{dS} / \mathrm{m})$ & $\mathrm{Na}^{+}(\mathrm{mg} / \mathrm{L})$ & $\mathrm{Ca}^{2+}(\mathrm{mg} / \mathrm{L})$ & $\mathrm{Mg}^{2+}(\mathrm{mg} / \mathrm{L})$ & $\mathrm{SAR}(\mathrm{mmol} / \mathrm{L})$ \\
\hline $\mathrm{CK}$ & $9.15 \pm 0.05 \mathrm{a}$ & $1.05 \mathrm{~h}$ & $334.59 \pm 9.06 \mathrm{f}$ & $28.70 \pm 1.14 \mathrm{f}$ & $10.43 \pm 0.38 \mathrm{f}$ & 19.17 \\
$\mathrm{NM}$ & $7.73 \pm 0.07 \mathrm{k}$ & $2.54 \mathrm{~b}$ & $585.83 \pm 9.70 \mathrm{c}$ & $44.44 \pm 1.04 \mathrm{c}$ & $41.18 \pm 0.55 \mathrm{ab}$ & 21.42 \\
$\mathrm{LS}$ & $7.93 \pm 0.10 \mathrm{i}$ & $1.81 \mathrm{f}$ & $470.35 \pm 12.23 \mathrm{~d}$ & $49.41 \pm 1.60 \mathrm{~b}$ & $15.82 \pm 0.55 \mathrm{e}$ & 21.01 \\
AL+NM & $7.72 \pm 0.09 \mathrm{k}$ & $2.28 \mathrm{c}$ & $581.85 \pm 10.57 \mathrm{c}$ & $40.63 \pm 1.58 \mathrm{~d}$ & $40.06 \pm 0.63 \mathrm{~b}$ & 21.83 \\
AL+LS & $7.53 \pm 0.07 \mathrm{l}$ & $2.41 \mathrm{~b}$ & $587.36 \pm 7.81 \mathrm{c}$ & $66.17 \pm 1.56 \mathrm{a}$ & $39.97 \pm 1.31 \mathrm{~b}$ & 19.82 \\
HH & $8.13 \pm 0.06 \mathrm{~g}$ & $2.2 \mathrm{c}$ & $484.52 \pm 12.35 \mathrm{~d}$ & $49.58 \pm 0.39 \mathrm{~b}$ & $35.78 \pm 1.19 \mathrm{c}$ & 18.03 \\
Z & $9.04 \pm 0.02 \mathrm{~b}$ & $0.89 \mathrm{i}$ & $177.00 \pm 7.33 \mathrm{~g}$ & $21.44 \pm 2.09 \mathrm{~g}$ & $4.88 \pm 0.16 \mathrm{j}$ & 12.66 \\
ZH & $8.78 \pm 0.02 \mathrm{c}$ & $0.94 \mathrm{i}$ & $185.90 \pm 4.60 \mathrm{~g}$ & $21.74 \pm 1.36 \mathrm{~g}$ & $5.95 \pm 0.07 \mathrm{i}$ & 12.85 \\
AL & $8.17 \pm 0.09 \mathrm{f}$ & $2.12 \mathrm{~d}$ & $677.65 \pm 11.53 \mathrm{a}$ & $65.99 \pm 0.68 \mathrm{a}$ & $42.48 \pm 1.65 \mathrm{a}$ & 22.53 \\
AL+Z & $8.51 \pm 0.09 \mathrm{~d}$ & $1.63 \mathrm{~g}$ & $480.52 \pm 16.35 \mathrm{~d}$ & $25.92 \pm 1.89 \mathrm{f}$ & $8.96 \pm 0.08 \mathrm{~g}$ & 29.23 \\
AL+ZH & $8.35 \pm 0.08 \mathrm{e}$ & $1.69 \mathrm{~g}$ & $478.52 \pm 6.03 \mathrm{~d}$ & $26.74 \pm 2.32 \mathrm{f}$ & $11.24 \pm 0.50 \mathrm{f}$ & 27.59 \\
ALCL & $7.97 \pm 0.08 \mathrm{i}$ & $2.85 \mathrm{a}$ & $632.10 \pm 11.87 \mathrm{~b}$ & $64.89 \pm 1.48 \mathrm{a}$ & $36.27 \pm 0.48 \mathrm{c}$ & 21.96 \\
ALCL+Z & $8.23 \pm 0.06 \mathrm{f}$ & $2.04 \mathrm{e}$ & $468.01 \pm 4.66 \mathrm{~d}$ & $25.63 \pm 0.91 \mathrm{f}$ & $9.10 \pm 0.07 \mathrm{~g}$ & 28.50 \\
ALCL+ZH & $8.11 \pm 0.02 \mathrm{gh}$ & $2.09 \mathrm{~d}$ & $491.72 \pm 9.81 \mathrm{~d}$ & $25.83 \pm 0.55 \mathrm{f}$ & $7.13 \pm 0.17 \mathrm{~h}$ & 31.14 \\
\hline
\end{tabular}

Note: The data in the table are average \pm standard deviation. There is no significant difference at 0.05 level in the same column of data with the same letters (Duncan's method). 
Table.3 Effects of different amendments on exchangeable $\mathrm{Na}^{+}, \mathrm{CEC}$ and ESP in soils

Note: The data in the table are average \pm standard deviation. There is no significant difference at 0.05 level in the same column of data with the same letters (Duncan's method).

Table.4 Effects of different amendments on yield components and yield of corn

\begin{tabular}{|c|c|c|c|c|c|}
\hline Time & Treatment & $\begin{array}{l}\text { Spike number } \\
\text { (Ten } \\
\text { thousand } / \mathrm{hm}^{2} \text { ) }\end{array}$ & $\begin{array}{l}\text { Spike grain } \\
\text { number }\end{array}$ & $\begin{array}{l}1000 \text { grain } \\
\text { weight/g }\end{array}$ & $\operatorname{Yield}\left(\mathrm{kg} / \mathrm{hm}^{2}\right)$ \\
\hline \multirow[t]{6}{*}{ First year } & CK & $185 \pm 8.67 \mathrm{~d}$ & $92 \pm 2.08 c$ & $13.6 \pm 0.35 \mathrm{c}$ & $2315.2 \pm 158.3 \mathrm{f}$ \\
\hline & $\mathrm{Z}$ & $242 \pm 7.64 \mathrm{c}$ & $90 \pm 1.73 \mathrm{c}$ & $15.0 \pm 0.46 \mathrm{bc}$ & $3268.4 \pm 266.6 \mathrm{e}$ \\
\hline & $\mathrm{ZH}$ & $275 \pm 12.22 \mathrm{bc}$ & $91 \pm 2.52 \mathrm{c}$ & $15.4 \pm 0.62 \mathrm{~b}$ & $3855.5 \pm 277.3 \mathrm{~d}$ \\
\hline & $\mathrm{AL}$ & $280 \pm 16.62 \mathrm{~b}$ & $122 \pm 6.00 \mathrm{a}$ & $17.8 \pm 1.27 \mathrm{a}$ & $6083.7 \pm 347.5 \mathrm{c}$ \\
\hline & $\mathrm{AL}+\mathrm{Z}$ & $339 \pm 18.08 \mathrm{a}$ & $110 \pm 3.79 \mathrm{~b}$ & $18.5 \pm 0.61 \mathrm{a}$ & $6902.1 \pm 56.6 \mathrm{~b}$ \\
\hline & $\mathrm{AL}+\mathrm{ZH}$ & $348 \pm 2.31 \mathrm{a}$ & $112 \pm 3.79 \mathrm{~b}$ & $19.4 \pm 0.15 \mathrm{a}$ & $7565.3 \pm 236.4 \mathrm{a}$ \\
\hline \multirow[t]{6}{*}{ Second year } & $\mathrm{CK}$ & $179 \pm 3.45 \mathrm{~d}$ & $90 \pm 1.35 \mathrm{c}$ & $13.1 \pm 0.75 \mathrm{e}$ & $2111.2 \pm 196.3 \mathrm{f}$ \\
\hline & $\mathrm{Z}$ & $250 \pm 8.75 \mathrm{c}$ & $91 \pm 3.78 \mathrm{c}$ & $15.3 \pm 0.33 \mathrm{~d}$ & $3482.5 \pm 300.4 \mathrm{e}$ \\
\hline & $\mathrm{ZH}$ & $286 \pm 15.24 \mathrm{~b}$ & $93 \pm 2.22 \mathrm{c}$ & $16.0 \pm 0.66 \mathrm{c}$ & $4108.6 \pm 298.4 \mathrm{~d}$ \\
\hline & $\mathrm{AL}$ & $297 \pm 10.98 b$ & $120 \pm 4.39 \mathrm{a}$ & $18.2 \pm 1.35 \mathrm{~b}$ & $6489.7 \pm 463.9 \mathrm{c}$ \\
\hline & $\mathrm{AL}+\mathrm{Z}$ & $345 \pm 11.65 \mathrm{a}$ & $116 \pm 5.12 \mathrm{ab}$ & $18.3 \pm 0.89 \mathrm{~b}$ & $7327.4 \pm 477.9 \mathrm{~b}$ \\
\hline & $\mathrm{AL}+\mathrm{ZH}$ & $352 \pm 6.64 \mathrm{a}$ & $122 \pm 7.79 \mathrm{a}$ & $19.5 \pm 0.28 \mathrm{a}$ & $8378.9 \pm 386.1 \mathrm{a}$ \\
\hline
\end{tabular}

Note: The data in the table are average \pm standard deviation. There is no significant difference at 0.05 level in the same column of data with the same letters (Duncan's method).

Table.5 Effects of different amendments on yield components and yield of rice

Note: The data in the table are average \pm standard deviation. There is no significant difference at 0.05 level in the same column of data with the same letters (Duncan's method). 

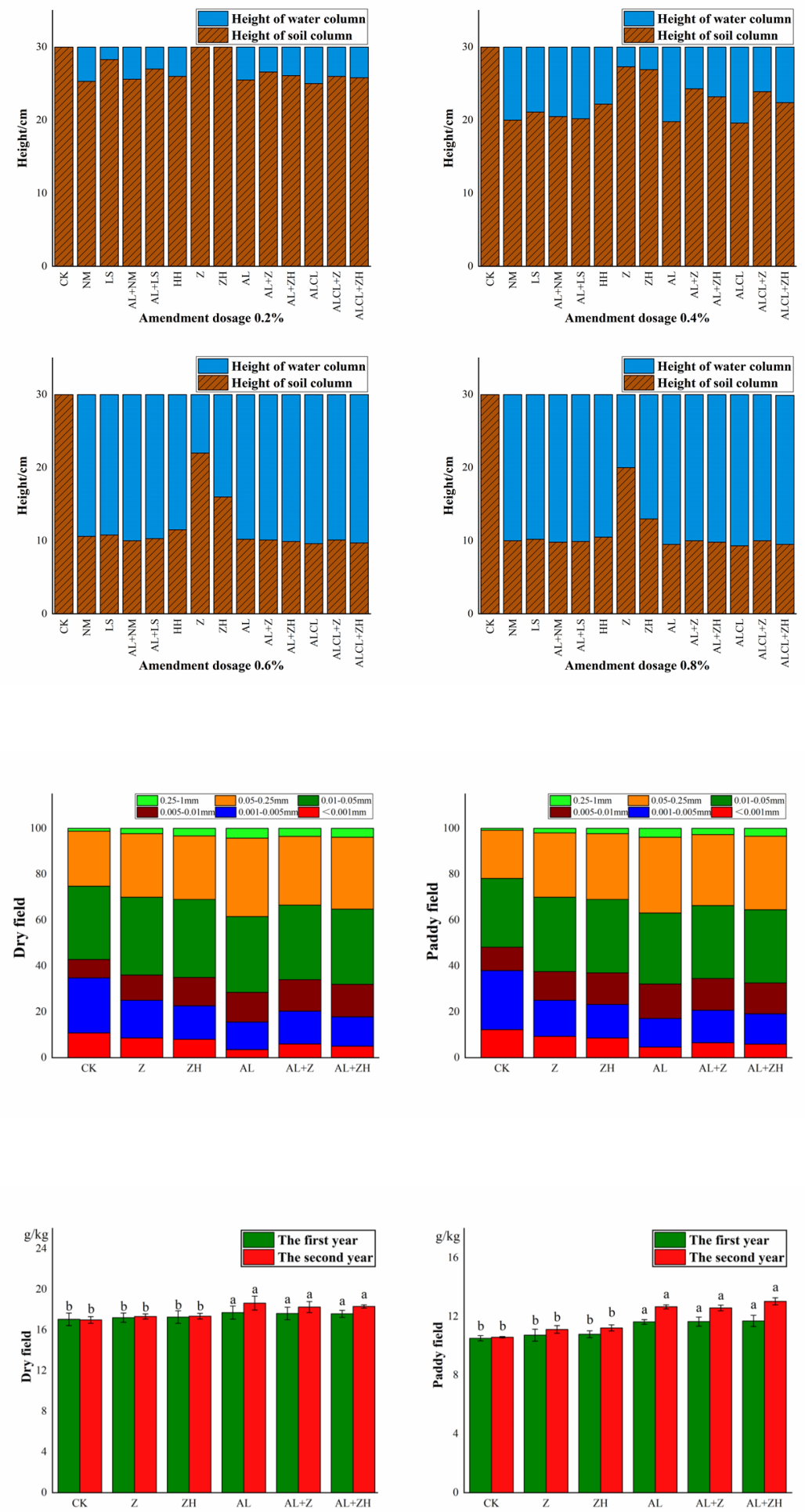